\title{
Validity and Reliability of the Adolescent Sedentary Activity Questionnaire (ASAQ) in Adolescents Aged Between 11 and 14
}

\section{Adölesan Sedanter Aktivite Anketi (ASAA)'nin 11 ile 14 Yaş Arasındaki Adölesanlarda Geçerlik ve Güvenirlik Çalışması}

\author{
Ayda Karaca, Necip Demirci \\ Recreation Department, Faculty of Sports Sciences, Hacettepe University, Ankara, Turkey
}

\begin{abstract}
A. Karaca
0000-0002-3189-2385

\section{N. Demirci \\ 0000-0003-0147-8332 \\ Geliş Tarihi/Date Received: 01.04.2019}

Kabul Tarihi/Date Accepted: 07.05.2019

Yayın Tarihi/Published Online: 15.09.2019

Yazışma Adresi /

Corresponding Author:

Ayda Karaca

Hacettepe Üniversitesi,

Rekreasyon Departmanı,

Ankara, Turkey

E-mail: aydakaraca@gmail.com

(C2019 Türkiye Spor Hekimleri Derneği. Tüm hakları saklıdır.

\begin{abstract}
Objective: It is essential to conduct validity and reliability studies of physical activity, inactivity, and sedentary behavior questionnaires due to increasing inactivity and sedentary lifestyle. The aim of the study was to evaluate the validity and reliability of the Turkish version of Adolescent Sedentary Activity Questionnaire (ASAQ) developed by Hardy, Booth, and Okely which has been adapted to Turkish culture.

Methods: The 5 to 8 th grade students (aged 11-14 years) were involved in the validity $(n=155)$ and reliability studies $(n=305)$. After cultural adaptation and pilot study, the validity and reliability of ASAQ were examined by using the intraclass correlation coefficient (ICC). Physical Activity Diary was used for the determination of the concurrent validity of ASAQ. To examine the test-retest reliability, the participants completed the ASAQ twice with one week interval.

Results: It was determined that the validity coefficient of total sedentary times of ASAQ for all week of children aged 11-14 years was moderate level (ICC=0.53). The validity coefficients of total sedentary times of ASAQ for the whole week of children aged $11,12,13,14$ years were found to be moderate level (respectively, ICC $=0.56$; ICC $=0.44 ; \mathrm{ICC}=0.44 ; \mathrm{ICC}=0.51$ ). The reliability coefficient of total sedentary times of ASAQ for all week of children aged 11-14 years was determined to be a good level $(I C C=0.71)$. While the reliability coefficient of total sedentary times of ASAQ for all week of children aged 11 and 12 years was founded to be excellent level (respectively, $I C C=0.79$; ICC $=0.77$ ), the reliability coefficient for children aged 13 and 14 years was seen to be a good level (respectively, ICC=0.64; ICC=0.69).

Conclusion: It was concluded that $A S A Q$ is a valid and reliable questionnaire that evaluates the sedentary activity times of weekdays, weekends and the total week of Turkish children between the ages of 11-14.

Keywords: Validity, reliability, adolescent, sedentary behavior
\end{abstract}

\section{Öz}

Amaç: İnaktivitenin ve sedanter yaşam tarzının giderek artması fiziksel aktivite, inaktivite ve sedanter davranış anketlerinin geçerlik ve güvenirlik çalışmalarının yapılmasını önemli hale getirmektedir. Hardy, Booth ve Okely tarafından geliştirilen Adölesan Sedanter Aktivite Anketi'ni (ASAA) Türk kültürüne uyarlanmış Türkçe versiyonunun geçerlik ve güvenirlik çalışması yapılmıştır.

Gereç ve Yöntemler: 11-14 yaşları arasında 5-8. sınıfta öğrenim gören 155 öğrenci


güvenirlik çalışmasına dahil edilmiştir. ASAA'nın kültürel uyarlama ve pilot çalışmasının ardından geçerlik ve güvenirlik çalışması yapılmıştır. 
ASAA'nın uyum geçerliğinin saptanmasında Fiziksel Aktivite Günlüğü kullanılmış ve hafta içi, hafta sonu, tüm hafta için oturma süreleri belirlenmiştir. ASAA ve Fiziksel Aktivite Günlüğünden elde edilen sedanter aktivite süreleri arasındaki ilişki Sınıf içi Korelasyon Katsayısı (SKK) ile değerlendirilerek uyum geçerliği saptanmıştır. ASAA'nın yedi gün arayla iki kez uygulanmasıyla elde edilen hafta içi sedanter süre, hafta sonu sedanter süre ve haftalık toplam sedanter süre arasındaki ilişki SKK kullanılarak analiz edilerek güvenirlik katsayısı saptanmıştır.

Bulgular: 11-14 yaşları arasındaki çocukların tüm hafta için ASAA'nın toplam sedanter aktivite süresine ait geçerlik katsayısının orta düzeyde olduğu (SKK=0,53) saptanmıştır. $11,12,13$ ve 14 yaşındaki çocukların tüm hafta için ASAA'nın toplam sedanter aktivite süresine ait geçerlik katsayılarının orta düzeyde (sırasıyla: $S K K=0,56$; $S K K=0,44$; $\mathrm{SKK}=0,44 ; \mathrm{SKK}=0,51$ ) olduğu belirlenmiştir. 11-14 yaşları arasındaki çocukların tüm hafta için ASAA'nın toplam sedanter aktivite süresine ait güvenirlik katsayısının iyi düzeyde olduğu (SKK=0,71) saptanmıştır. 11 ve 12 yaşındaki çocukların tüm hafta için toplam sedanter aktivite süresine ait güvenirlik katsayılarının çok iyi (sırasıyla: $\mathrm{SKK}=0,79$; SKK=0,77) düzeyde olduğu, 13 ve 14 yaşındaki çocukların tüm hafta için toplam sedanter aktivite süresine ait güvenirlik katsayılarının iyi düzeyde (sırasıyla: $S K K=0,64$; $S K K=0,69$ ) olduğu belirlenmiştir.

Sonuç: 11-14 yaşları arasındaki Türk çocuklarının hafta içi, hafta sonu ve tüm haftaya ait sedanter aktivite sürelerinin değerlendirildiği ASAA'nın geçerli ve güvenilir bir anket olduğu sonucuna ulaşılmıştır.

Anahtar Sözcükler: Geçerlik, güvenirlik, adölesan, sedanter davranış

Available at: http://journalofsportsmedicine.org and http://dx.doi.org/10.5152/tjsm.2019.140

Cite this article as: Karaca A, Demirci N. Validity and Reliability of the Adolescent Sedentary Activity Questionnaire (ASAQ) in adolescents aged between 11and 14. Turk J Sports Med. 2019;54(4):255-66.

\section{GíRiș}

Sedanter aktivite (SA) oturma, uzanma gibi uyanık olma durumunda yapılan, 1,5 MET ve altında enerji harcanmasına neden olan her türlü hareket olarak tanımlanmaktadır (1). Televizyon izleme, bilgisayar kullanma, elektronik oyunlar oynama, telefonda konuşma, ev ödevi yapma, kitap okuma, motorlu taşıtlarla ulaşım gençlerde sedanter zamanı artıran aktivitelerdir. İnaktivite tanımı ise fiziksel aktivite (FA) önerilerinin karşılanamadığı, yetersiz fiziksel aktiviteyi içerir (1). SA ve inaktivitenin aynı anlama gelip gelmediği tartışılmakla beraber, her ikisinin de sağlık açısından pek çok olumsuz etkileri olduğu bilinmekte (2-4) ve halk sağlığ stratejilerinde ikisi için de eş zamanlı olarak hedeflerin belirlenmesi önerilmektedir (4). Amerikan Pediatri Akademisi sedanter aktivitelerin çocuk ve adölesanların sağlığına zarar verebileceğini ve ekran/medya kullanımına sınırlama getirilmesi gerektiğini vurgulamaktadır (5). Çocukluk döneminde artan FA düzeyi optimal iskelet gelişimine katkı sağlarken, kardiyovasküler ve metabolik hastalık risk faktörlerini azaltmaktadır (6). Ayrıca çocuklarda inaktivitenin artmasına bağlı olarak obezite, kan lipitlerinin yükselmesi, hipertansiyon, diyabet gibi kronik hastalıkların görülme riski giderek artmaktadır (7).

Endüstrileşmenin artması ile birlikte FA düzeyi giderek azalmıştır (8). Dünya Sağlık Ör- gütü'nün 2010 yılı verilerine göre okula devam eden 11-17 yaşları arasındaki adölesanların önerilen düzeyde FA yapmama oranının küresel düzeyde \%81 (kızlarda \%84; erkeklerde \%78), Türkiye'de \%82,2 (kızlarda \%86,9; erkeklerde $\% 77,1$ ) olduğu görülmüştür (9). Çocukluk çağı obezitesinin günümüzde artış göstermesinin nedenleri kesin olarak tanımlanamazken, FA düzeyindeki azalmanın, çocuklarda obeziteyi büyük ölçüde artırdığı bilinmektedir (10). Bucksch ve ark. (11) yaptıkları çalışmada adolesanların 2002 ve 2010 yılları arasında ekran karşısında geçirdikleri sürelerin arttı̆̆ını belirtmişlerdir. Guthold ve ark. (12) 34 ülkede 72.847 öğrenci üzerinde yaptıkları araştırmada 13-15 yaşları arasındaki öğrencilerin büyük çoğunluğunun FA önerilerini karşılamadığını ve sedanter aktivite süresinin yüksek olduğunu vurgulamışlardır. Dolayısıyla acilen harekete geçilmesi ve dünya genelinde bu yaş grubu adölesanların FA düzeylerini artırmaya yönelik çaba harcanması gerekliliği ortaya konulmuştur (12).

SA ve FA düzeyinin değerlendirilmesinde anket yönteminin kullanıldığı pek çok çalışmaya rastlanmaktadır. Düşük maliyetli olması, daha az iş gücü gerektirmesi, katılımcı yükünün az olması ve büyük ölçekli araştırmalarda kullanılabilmesi anket yönteminin avantajlarından olup $(2,13)$ sedanter davranışın süresi, 
tipi ve bağlamı da anket yöntemiyle değerlendirilebilmektedir (2). Araştırmalarda kullanılacak anketlerin güvenilir, geçerli ve kullanışlı olması FA ve sedanter davranışın doğru bir şekilde belirlenebilmesi açısından önemlidir (13, 14). Uluslararası literatürde çocuklar için geliştirilmiş pek çok SA anketi bulunmaktadır (14). Ülkemizde ise adölesanlarda sedanter davranışın değerlendirilmesinde kullanılan geçerlik ve güvenirlik çalışması yapılmış ankete rastlanmamıştır.

İnaktivite ve SA süresinin azaltılması amacıyla ülkelerin kendilerine özgü stratejileri mevcuttur (15). Stratejilerin belirlenmesi için FA düzeyinin, inaktivite ve SA süresinin bilinmesi gereklidir (16). Halk sağlığ yapılacak araștırmalar için sedanter davranıșın geçerli ve güvenilir bir yöntemle ölçülmesi (2), FA düzeyinin belirlenmesi ve düşük düzeyde aktif olan bireylerin fiziksel aktiviteye yönlendirilmesi açısından oldukça önem taşımaktadır (16). Giderek artan inaktivitenin ve sedanter yaşam tarzının takip edilmesinin gerekliliği, kolay uygulanabilir ve maliyeti düşük olan FA, inaktivite ve SA anketlerinin geçerlik ve güvenirlik çalışmalarının yapılmasını önemli hale getirmektedir. Dolayısıyla ülkemizde sedanter davranışı değerlendiren herhangi bir anketin olmamasından yola çıkılarak planlanan bu çalışmanın amacl; Hardy, Booth ve Okely tarafından geliștirilen Adölesan Sedanter Aktivite Anketi'nin (Adolescent Sedentary Activity Questionnaire) Türk diline ve kültürüne uyarlama geçerlik ve güvenirlik çalışmasının yapılmasıdır.

\section{GEREÇ VE YÖNTEMLER}

\section{Araştırma Grubu}

Geçerlik çalışmasına 11-14 yaşları arasında 5-8. sınıfa devam eden, yaş ortalaması $12,43 \pm 1,09$ olan $104 \mathrm{klz}$ ve 51 erkek olmak üzere toplamda 155 ortaokul öğrencisi dahil edilmiştir. Güvenirlik çalıșmasına ise 11-14 yaşları arasında 5-8. sınıfa devam eden, yaş ortalaması $12,59 \pm 1,06$ olan $171 \mathrm{kız}$ ve 134 erkek olmak üzere toplamda 305 ortaokul öğrencisi dahil edilmiştir. Ölçümler Ankara ilinde MEB'e bağlı özel ve devlet ortaokullarında, Ankara İl Milli Eğitim Müdürlügü'nün izni (sayı: 14588481-605.99-
E.22597072) ile gerçekleștirilmiştir. Çalışma öncesi Hacettepe Üniversitesi Girişimsel Olmayan Araştırmalar Etik Kurulu'ndan etik kurul izni (GO 18/322-30) alınmıştır. ASAA öğrencilere kendini değerlendirme yöntemiyle uygulanmıştır.

\section{Veri Toplama Araçları}

Adölesan Sedanter Aktivite Anketi (ASAA): Adölesan Sedanter Aktivite Anketi (Adolescence Sedentary Activity Questionnaire (ASAQ) Hardy, Booth ve Okely tarafından 2007 yılında geliştirilmiş ve güvenirlik çalışması yapılmıştır. ASAA'ın Türkiye'ye uyarlama, geçerlik ve güvenirlik çalışmasının yapılması için Louise L. Hardy'den e-posta yoluyla izin alınmıştır. ASAA'nın orijinalinde hafta içi günler için 11 soru hafta sonu günler için 12 soru mevcuttur. ASAA hafta içi her bir gün için okul öncesi ve okul sonrasındaki zaman dilimini, hafta sonu günler için günün tüm saatlerini kapsamaktadır. Türkçeye uyarlanan ASAA 10 farklı SA için harcanan süreyi içermektedir. Böylece sedanter aktiviteler için tüm hafta, hafta içi ve hafta sonu günlere kadar harcanan süreler hesaplanabilmektedir. ASAA Tablo 1'de verilen beş farklı SA kategorisinden oluşmaktadır. Bu bağlamda her bir aktivite kategorisinde harcanan süreler hesaplanabilmektedir. ASAA ile beș SA kategorisinde hafta içi, hafta sonu ve tüm hafta için SA süreleri hesaplanabilmektedir (17). ASAA'nın Kategorileri ve Bileșenleri Tablo 1'de verilmiştir.

Fiziksel Aktivite Günlüğü: Karaca (18) tarafından hazırlanan FA Günlüğü formu haftanın her günü için sabah, öğleden sonra ve akșam olmak üzere üç farklı zaman dilimine ait oturma, yürüme, koşma-zıplama-spor yapma-hareketli olma süresini (günde kaç saat ya da dakika yapıldığını) içermektedir. Bu çalışmada sadece oturma süresi haftanın günlerine göre belirlenmiştir.

Kişisel Bilgi Formu: Araştırmacılar tarafından hazırlanmış olup demografik bilgileri içermektedir. 
Tablo 1. Adölesan Sedanter Aktivite Anketinin (ASAA) Kategorileri ve Bileşenleri

\begin{tabular}{|c|c|}
\hline Sedanter Kategori & Sedanter Aktivite \\
\hline $\begin{array}{l}\text { Ekran karşısında } \text { geçirilen } \\
\text { rekreasyonel } \\
\text { (EKGRZ) }\end{array}$ & $\begin{array}{l}\text { TV, Video ve DVD izlemek, video oyunları oynamak, e-iletişim, eğlenmek için } \\
\text { bilgisayar kullanmak, e-oyunlar, internette gezinmek }\end{array}$ \\
\hline Eğitim & $\begin{array}{l}\text { Ev ödevi yapmak için bilgisayar kullanmak, bilgisayar kullanmadan ev ödevi } \\
\text { yapmak }\end{array}$ \\
\hline Ulaşım & Motorlu taşıt (araba, otobüs, tren) \\
\hline Kültürel Aktiviteler & $\begin{array}{l}\text { Eğlence için okumak, el işi veya hobiler, kutu ve kart oyunları, enstrüman } \\
\text { çalmak/pratiğini yapmak }\end{array}$ \\
\hline Sosyal Aktiviteler & $\begin{array}{l}\text { Oturarak vakit geçirmek (arkadaşlarla telefonda konuşmak, sohbet etmek), } \\
\text { müzik dinlemek }\end{array}$ \\
\hline
\end{tabular}

\section{Verilerin Toplanması}

\section{Adölesan Sedanter Aktivite Anketi'nin Kül- türel Uyarlama Çalışması}

Hardy ve arkadaşları tarafından 2007 yılında geliştirilen ASAA, İngilizcenin yapısını iyi tanıyan ve İngilizceye hakim olan deneyimli kişiler (1 dil bilimci, 2 spor bilimci) tarafindan Türkçe'ye daha sonra da tekrar İngilizceye çevrilmiştir. Anketin Türkçeye çevirisi yapıldıktan sonra pilot çalıșma yapılarak ne kadar anlaşılabilir olduğu değerlendirilmiştir. Hafta sonu günlerde yer alan 'kiliseye gitmek ya da cumartesi okula gitmek' sorusu pilot çalışma öncesinde çıkarılmıştır. Pilot çalışmadan sonra anketin orijinalinde yer alan 'özel ders alma' sorusu hem hafta içi hem de hafta sonu günlerden çıkarılmıştır. Kültürel uyarlama çalışması tamamlandıktan sonra anketin geçerlik ve güvenirlik çalışmaları yapılmıştır.

\section{Adölesan Sedanter Aktivite Anketi'nin Geçer- lik Çalışması}

ASAA'nın uyum geçerliğini saptamak amacıyla FA günlüğü kullanılmış ve haftanın günlerine (hafta içi, hafta sonu, tüm hafta) göre oturma süresi belirlenmiştir. Geçerlik çalışması için okullara iki ziyaret gerçekleştirilmiştir. İlk ziyarette öğrencilere FA günlüğü verilmiş ve nasıl dolduracakları açıklanmıştır. Öğrencilerden yedi gün süresince formu her gün doldurmaları ve sekizinci günde geri getirmeleri istenmiştir. İkinci ziyarette FA günlügünü dolduran öğrencilere ASAA kendini değerlendirme yöntemiyle uygulanmıştır. Her bir yaş grubu için elde edilen hafta içi, hafta sonu ve tüm haftaya ait olmak üzere ASAA'dan elde edilen SA süresi ile FA günlügünden elde edilen oturma süresi arasındaki ilişki katsayısı hesaplanarak geçerlik katsayıları elde edilmiştir.

\section{Adölesan Sedanter Aktivite Anketi'nin Güve- nirlik Çalışması}

ASAA'nın güvenirliğini saptamak amacıyla okullara iki ziyaret gerçekleştirilmiştir. Yedi gün arayla gerçekleştirilen her iki ziyarette (testtekrar test) öğrencilere ASAA kendini değerlendirme yöntemiyle uygulanmıştır. ASAA testtekrar test uygulamasından sonra her bir yaş grubu için elde edilen hafta içi, hafta sonu ve tüm haftaya ait oturma süreleri arasındaki ilişki katsayısının hesaplanmasıyla güvenirlik katsayıları elde edilmiştir.

\section{Verilerin Analizi}

Geçerlik katsayısının belirlenmesi amacıyla FA günlügünden elde edilen oturma süresi ile ASAA'dan elde edilen SA süresi arasındaki ilişki her iki ölçüm yönteminden elde edilen verilere ait birimlerin aynı (saat/hafta) olması nedeniyle Sınıf İçi Korelasyon Katsayısı (SKK) kullanılarak belirlenmiștir. Güvenirlik katsayısının belirlenmesi amaciyla ASAA bir hafta arayla iki kez (test-tekrar test) uygulanmış ve SA sürelerine ilişkin (hafta içi, hafta sonu ve haftalık toplam) güvenirlik katsayıları SKK kullanılarak saptanmıştır. 
ASAA'nın geçerlik ve güvenirliğinin belirlendiği bu çalışmada Sınıf İçi Korelasyon Katsayısının kabul edilebilir seviyeleri (zaylf: $<0,40$; orta:
0,40-0,59; iyi: 0,60-0,74; çok iyi: >0,74) Barrett'e (19) göre belirlenmiştir.

Tablo 2. ASAA'nın yaşa göre hafta içi, hafta sonu ve tüm haftaya ilişkin geçerlik katsayıları



Sınıf içi Korelasyon Katsayısı (SKK); Güven Aralığı (GA) 


\section{BULGULAR}

ASAA'nın sedanter aktivite süresi (saat/hafta) ile FA günlüğünün oturma süresi (saat/hafta) arasındaki ilişki incelenmiş ve yaşa göre SA sürelerine (tüm hafta, hafta içi, hafta sonu) ait geçerlik katsayıları Tablo 2'de verilmiştir.

11-14 yaşları arasındaki çocukların tüm hafta için toplam SA süresine ait geçerlik katsayısının orta düzeyde olduğu $(\mathrm{SKK}=0,53)$ saptanmıştır. ASAA'nın geçerlik katsayıları yaşa ve haftanın günlerine göre incelenmiş olup 11, 14 ve 11-14 yaşlarındaki öğrencilerin hafta sonu ASAA'dan elde edilen $S A$ süreleri ve aktivite günlügünden elde edilen hafta sonu oturma süreleri arasındaki ilişkinin incelendiği SKK'larının iyi düzeyde olduğu, diğer korelasyon katsayılarının ise orta düzeyde olduğu görülmüştür (Tablo 2). ASAA'nın tüm yaşlarda hafta sonu SA sürelerine ait geçerlik katsayılarının hafta içinden yüksek olduğu görülmüştür (Tablo 2).

Tablo 3. ASAA'nin yaşa göre hafta içi, hafta sonu ve tüm haftaya ilişkin sedanter davranış sürelerinin test-tekrar test güvenirlik katsayıları

\begin{tabular}{|c|c|c|c|c|c|c|}
\hline & & $\begin{array}{l}11 \text { yaş } \\
(n=59)\end{array}$ & 12 yaş $(n=84)$ & 13 yaş $(n=84)$ & 14 yaş $(n=78)$ & $\begin{array}{l}11-14 \\
(n=305)\end{array}$ \\
\hline & & $\begin{array}{l}\text { SKK } \\
\text { (\%95-GA) } \\
\text { (p değeri) }\end{array}$ & $\begin{array}{l}\text { SKK } \\
\text { (\%95-GA) } \\
\text { (p değeri) }\end{array}$ & $\begin{array}{l}\text { SKK } \\
\text { (\%95-GA) } \\
\text { (p değeri) }\end{array}$ & $\begin{array}{l}\text { SKK } \\
(\% 95-G A) \\
\text { (p değeri) }\end{array}$ & $\begin{array}{l}\text { SKK } \\
\text { (\%95-GA) } \\
\text { (p değeri) }\end{array}$ \\
\hline \multirow{6}{*}{ 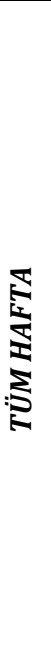 } & Toplam & $\begin{array}{l}0,79 \\
(0,64-0,87) \\
(0,00)\end{array}$ & $\begin{array}{l}0,77 \\
(0,65-0,85) \\
(0,01)\end{array}$ & $\begin{array}{l}0,64 \\
(0,44-0,77) \\
(0,01)\end{array}$ & $\begin{array}{l}0,69 \\
(0,51-0,80) \\
(0,01)\end{array}$ & $\begin{array}{l}0,71 \\
(0,64-0,77) \\
(0,01)\end{array}$ \\
\hline & EKGRZ $^{a}$ & $\begin{array}{l}0,84 \\
(0,74-0,91) \\
(0,01)\end{array}$ & $\begin{array}{l}0,94 \\
(0,91-0,96) \\
(0,01)\end{array}$ & $\begin{array}{l}0,79 \\
(0,67-0,86) \\
(0,01)\end{array}$ & $\begin{array}{l}0,87 \\
(0,79-0,92) \\
(0,01)\end{array}$ & $\begin{array}{l}0,88 \\
(0,85-0,90) \\
(0,01)\end{array}$ \\
\hline & Eğitim & $\begin{array}{l}0,78 \\
(0,63-0,87) \\
(0,01)\end{array}$ & $\begin{array}{l}0,77 \\
(0,65-0,86) \\
(0,01)\end{array}$ & $\begin{array}{l}0,45 \\
(0,14-0,64) \\
(0,01)\end{array}$ & $\begin{array}{l}0,88 \\
(0,81-0,92) \\
(0,01)\end{array}$ & $\begin{array}{l}0,73 \\
(0,66-0,79) \\
(0,01)\end{array}$ \\
\hline & Ulaşım & $\begin{array}{l}0,46 \\
(0,09-0,68) \\
(0,01)\end{array}$ & $\begin{array}{l}0,64 \\
(0,43-0,77) \\
(0,01)\end{array}$ & $\begin{array}{l}0,39 \\
(0,06-0,61) \\
(0,01)\end{array}$ & $\begin{array}{l}0,77 \\
(0,64-0,86) \\
(0,01)\end{array}$ & $\begin{array}{l}0,52 \\
(0,40-0,62) \\
(0,01)\end{array}$ \\
\hline & $\begin{array}{l}\text { Kültürel } \\
\text { Aktiviteler }\end{array}$ & $\begin{array}{l}0.69 \\
(0,48-0,82) \\
(0,01)\end{array}$ & $\begin{array}{l}0,46 \\
(0,17-0,65) \\
(0,01)\end{array}$ & $\begin{array}{l}0,85 \\
(0,76-0,90) \\
(0,01)\end{array}$ & $\begin{array}{l}0,44 \\
(0,11-0,64) \\
(0,01)\end{array}$ & $\begin{array}{l}0,58 \\
(0,47-0,67) \\
(0,01)\end{array}$ \\
\hline & $\begin{array}{l}\text { Sosyal } \\
\text { Aktiviteler }\end{array}$ & $\begin{array}{l}0,54 \\
(0,22-0,73) \\
(0,01)\end{array}$ & $\begin{array}{l}0,66 \\
(0,47-0,78) \\
(0,01)\end{array}$ & $\begin{array}{l}0,74 \\
(0,59-0,83) \\
(0,01)\end{array}$ & $\begin{array}{l}0,68 \\
(0,50-0,80) \\
(0,01)\end{array}$ & $\begin{array}{l}0,71 \\
(0,64-0,77) \\
(0,01)\end{array}$ \\
\hline \multirow{6}{*}{ 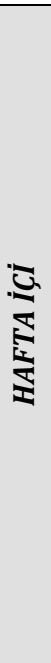 } & Toplam & $\begin{array}{l}0,75 \\
(0,58-0,85) \\
(0,01)\end{array}$ & $\begin{array}{l}0,63 \\
(0,42-0,76) \\
(0,01)\end{array}$ & $\begin{array}{l}0,42 \\
(0,10-0,62) \\
(0,01)\end{array}$ & $\begin{array}{l}0,66 \\
(0,46-0,78) \\
(0,01)\end{array}$ & $\begin{array}{l}0,58 \\
(0,47-0,67) \\
(0,01)\end{array}$ \\
\hline & EKGRZ & $\begin{array}{l}0,80 \\
(0,67-0,86) \\
(0,01)\end{array}$ & $\begin{array}{l}0,91 \\
(0,86-0,94) \\
(0,01)\end{array}$ & $\begin{array}{l}0,69 \\
(0,52-0,80) \\
(0,01)\end{array}$ & $\begin{array}{l}0,86 \\
(0,77-0,91) \\
(0,01)\end{array}$ & $\begin{array}{l}0,81 \\
(0,60-0,74) \\
(0,01)\end{array}$ \\
\hline & Eğitim & $\begin{array}{l}0,72 \\
(0,54-0,83) \\
(0,01)\end{array}$ & $\begin{array}{l}0,67 \\
(0,49-0,78) \\
(0,01)\end{array}$ & $\begin{array}{l}0,40 \\
(0,79-0,61) \\
(0,01)\end{array}$ & $\begin{array}{l}0,73 \\
(0,61-0,82) \\
(0,01)\end{array}$ & $\begin{array}{l}0,68 \\
(0,47-0,66) \\
(0,01)\end{array}$ \\
\hline & Ulaşım & $\begin{array}{l}0,49 \\
(0,14-0,70) \\
(0,01)\end{array}$ & $\begin{array}{l}0,56 \\
(0,32-0,72) \\
(0,01)\end{array}$ & $\begin{array}{l}0,80 \\
(0,69-0,87) \\
(0,01)\end{array}$ & $\begin{array}{l}0,78 \\
(0,66-0,86) \\
(0,01)\end{array}$ & $\begin{array}{l}0,72 \\
(0,65-0,78) \\
(0,01)\end{array}$ \\
\hline & $\begin{array}{l}\text { Kültürel } \\
\text { Aktiviteler }\end{array}$ & $\begin{array}{l}0,79 \\
(0,65-0,87) \\
(0,01)\end{array}$ & $\begin{array}{l}0,40 \\
(0,08-0,61) \\
(0,01)\end{array}$ & $\begin{array}{l}0,81 \\
(0,71-0,87) \\
(0,01)\end{array}$ & $\begin{array}{l}0,32 \\
(-0,07-0,56) \\
(0,05)\end{array}$ & $\begin{array}{l}0,51 \\
(0,38-0,61) \\
(0,01)\end{array}$ \\
\hline & $\begin{array}{l}\text { Sosyal } \\
\text { Aktiviteler }\end{array}$ & $\begin{array}{l}0,51 \\
(0,17-0,71) \\
(0,01)\end{array}$ & $\begin{array}{l}0,57 \\
(0,34-0,72) \\
(0,01)\end{array}$ & $\begin{array}{l}0,68 \\
(0,51-0,79) \\
(0,01)\end{array}$ & $\begin{array}{l}0,61 \\
(0,38-0,75) \\
(0,01)\end{array}$ & $\begin{array}{l}0,65 \\
(0,56-0,72) \\
(0,01)\end{array}$ \\
\hline
\end{tabular}




\begin{tabular}{|c|c|c|c|c|c|c|}
\hline \multirow{6}{*}{ 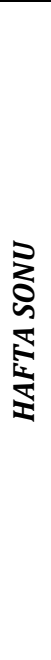 } & Toplam & $\begin{array}{l}0,71 \\
(0,50-0,83) \\
(0,01)\end{array}$ & $\begin{array}{l}0,85 \\
(0,77-0,90) \\
(0,01)\end{array}$ & $\begin{array}{l}0,65 \\
(0,45-0,77) \\
(0,01)\end{array}$ & $\begin{array}{l}0,63 \\
(0,42-0,77) \\
(0,01)\end{array}$ & $\begin{array}{l}0,73 \\
(0,66-0,78) \\
(0,01)\end{array}$ \\
\hline & EKGRZ & $\begin{array}{l}0,74 \\
(0,56-0,85) \\
(0,01)\end{array}$ & $\begin{array}{l}0,94 \\
(0,90-0,96) \\
(0,01)\end{array}$ & $\begin{array}{l}0,83 \\
(0,73-0,89) \\
(0,01)\end{array}$ & $\begin{array}{l}0,82 \\
(0,72-0,89) \\
(0,01)\end{array}$ & $\begin{array}{l}0,88 \\
(0,85-0,91) \\
(0,01)\end{array}$ \\
\hline & Ĕgitim & $\begin{array}{l}0,67 \\
(0,44-0,80) \\
(0,01)\end{array}$ & $\begin{array}{l}0,67 \\
(0,49-0,79) \\
(0,01)\end{array}$ & $\begin{array}{l}0,47 \\
(0,18-0,66) \\
(0,01)\end{array}$ & $\begin{array}{l}0,71 \\
(0,54-0,81) \\
(0,01)\end{array}$ & $\begin{array}{l}0,64 \\
(0,55-0,71) \\
(0,01)\end{array}$ \\
\hline & Ulaşım & $\begin{array}{l}0,45 \\
(0,06-0,67) \\
(0,01)\end{array}$ & $\begin{array}{l}0,59 \\
(0,36-0,74) \\
(0,01)\end{array}$ & $\begin{array}{l}0,72 \\
(0,56-0,82) \\
(0,01)\end{array}$ & $\begin{array}{l}0,42 \\
(0,08-0,63) \\
(0,01)\end{array}$ & $\begin{array}{l}0,55 \\
(0,43-0,64) \\
(0,01)\end{array}$ \\
\hline & $\begin{array}{l}\text { Kültürel } \\
\text { Aktiviteler }\end{array}$ & $\begin{array}{l}0,40 \\
(-0,16-0,65) \\
(0,03)\end{array}$ & $\begin{array}{l}0,71 \\
(0,54-0,81) \\
(0,01)\end{array}$ & $\begin{array}{l}0,82 \\
(0,72-0,89) \\
(0,01)\end{array}$ & $\begin{array}{l}0,83 \\
(0,73-0,89) \\
(0,01)\end{array}$ & $\begin{array}{l}0,73 \\
(0,66-0,78) \\
(0,01)\end{array}$ \\
\hline & $\begin{array}{l}\text { Sosyal } \\
\text { Aktiviteler }\end{array}$ & $\begin{array}{l}0,36 \\
(-0,08-0,62) \\
(0,04)\end{array}$ & $\begin{array}{l}0,52 \\
(0,25-0,69) \\
(0,01)\end{array}$ & $\begin{array}{l}0,70 \\
(0,53-0,80) \\
(0,01) \\
\end{array}$ & $\begin{array}{l}0,43 \\
(0,10-0,64) \\
(0,01) \\
\end{array}$ & $\begin{array}{l}0,54 \\
(0,42-0,63) \\
(0,01)\end{array}$ \\
\hline
\end{tabular}

aEkran Karşısında Geçirilen Rekreasyonel Zaman (EKGRZ); Sınıf içi Korelasyon Katsayısı (SKK); Güven Aralığı (GA)

Bir hafta arayla iki kez uygulanan ASAA'dan elde edilen SA süreleri arasındaki ilişki her bir yaş, haftanın günleri ve her bir SA kategorisine göre incelenmiş olup güvenirlik katsayıları Tablo 3 'te verilmiştir.

Tablo 3'te belirtildiği gibi 11, 12, 13 ve 14 yaşlarındaki öğrencilerde hafta içi (SKK= 0,42 ile 0,75 arasinda), hafta sonu (SKK=0,63 ile 0,85 arasında) ve tüm hafta (SKK=0,64 ile 0,79 arasında) için tüm kategorileri içeren toplam SA süresinin orta ve yüksek düzeyde güvenilir olduğu saptanmıştır. 11-14 yaşları arasındaki çocukların hafta içi, hafta sonu ve tüm hafta için tüm kategorileri içeren toplam SA sürelerine ait test-tekrar test güvenirlik katsayılarının 0,58 ile 0,73 arasında olduğu ve her bir kategoriye ait SA sürelerine ait sınıf içi korelasyon katsayılarının 0,32 ile 0,94 arasında olduğu saptanmıştır. 1114 yaşları arasındaki tüm çocuklar birlikte ele alındığında ASAA'nın güvenirlik katsayısı 0,71 olarak bulunmuştur.

\section{TARTIŞMA}

ASAA'nın dil ve kültürel uyarlamasının geçerlik ve güvenirliğinin test edilmesi bu çalışmanın amacını oluşturmaktadır. $\mathrm{Bu}$ çalışmada ASAA'nın 11-14 yaşları arasındaki çocuklarda geçerli ve güvenilir olduğu saptanmıştır. Hardy ve arkadaşları (17) tarafından geliştirilen ASAA'nın orijinalinin test-tekrar test güvenirlik katsayısı orta ve iyi, görünüş geçerliği ise iyi düzeydedir.

\section{Geçerlik Çalışması:}

11-14 yaşları arasındaki Türk çocuklarının hafta içi, hafta sonu ve tüm haftaya ait SA sürelerini değerlendiren ASAA ile FA Günlüğünden elde edilen oturma süresi arasındaki ilişki sınıf içi korelasyon katsayısı ile değerlendirilmiş ve geçerlik katsayısının orta ve iyi düzeyde olduğu saptanmıştır (Tablo 2).

Adölesanlarda SA'yı değerlendiren anketlere az sayıda rastlanılmaktadır. ASAA'nın geçerlik katsayıları yaşa ve haftanın günlerine (tüm hafta, hafta içi ve hafta sonu) göre incelenmiş olup her bir yaş için hafta sonuna ait geçerlik katsayısının hafta içi ve tüm haftaya ait korelasyon katsayılarından yüksek olduğu görülmüştür (Tablo 2). Bu çalışmada elde edilen geçerlik katsayılarının Busschaert ve ark. (20), CabanasSánchez ve ark. (24) ve Voss ve ark. (21) tarafından yapılan çalışmalarda elde edilen Spearman Rho korelasyon katsayılarından daha yüksek olduğu görülmüştür. Busschaert ve ark. (20) yaptıkları çalışmada SA düzeyinin ölçümünde kullandıkları anketin hafta içine ait korelasyon katsayısının $(r h o=0,42 ; \% 95 \mathrm{GA})$, hafta sonu $(r h o=0,02 ; \% 95 \mathrm{GA})$ ve tüm haftaya ait korelasyon katsayısından (rho=0,29; \%95GA) daha yüksek düzeyde olduğunu belirtmişlerdir. Voss ve ark. (21) yaptıkları çalışmada konjenital 
kalp rahatsızlığı olan çocuk ve adölesanlarda FA anketinin (PAQ-C ve PAQ-A) geçerlik katsayısının orta düzeyde ( $r h o=-0,53 ; \mathrm{p}<0.001)$ olduğunu saptamışlardır. FA anketinden elde edilen sedanter zamana ilişkin geçerlik katsayısının hafta sonu günlerde (rho $=-0,38$; $\mathrm{p}<0.01)$ tüm haftadan $(r h o=-0,48 ; \mathrm{p}<0,001)$ daha düşük olduğu görülmüștür (21). CabanasSánchez ve ark. (24) yaptıkları çalışmada Youth Leisure-time Sedentary Behavior Questionnaire'in geçerlik katsayısının (sırasıyla $r=0,36$; $r=0,20 ; r=0,36$;) düşük düzeyde olduğunu belirtmişlerdir. Schmitz ve ark. (22) ASAA'da her bir aktiviteye harcanan sürenin hafta içi ve hafta sonunu ayırabilecek şekilde hesaplanabilmesinin, özellikle ekran karşısında geçirilen rekreasyonel zaman (EKGRZ) aktivitelerinin geçerliğini artırdığını vurgulamışlardır. Bu çalışmada 11-14 yaşlarda ASAA'nın hafta sonuna ait geçerlik katsayısının hafta içi ve tüm haftaya ait SA süresinden daha iyi düzeydedir. Bunun nedeni SA türlerinin hafta içi ve hafta sonunda farklılık gösterebilmesi ve TV izleme, internet kullanma ve bilgisayarda oyun oynama gibi aktivitelerin daha geniş bir zaman dilimi olan hafta sonunda ebeveynler ya da çocuklar tarafından belirlenen bir plan dahilinde uygulanması olabililir.

\section{Güvenirlik Çalışması:}

11-14 yaşları arasındaki Türk çocuklarının hafta içi, hafta sonu ve tüm haftaya ait SA sürelerini beş kategoride (ekran karşısında geçirilen rekreasyonel zaman, eğitim, ulaşım, kültürel aktiviteler ve sosyal aktiviteler) değerlendiren ASAA'nın güvenilir bir anket olduğu saptanmıştır. Bütün kategorilerin dahil olduğu toplam skor tüm hafta için incelendiğinde ASAA'nın güvenirlik katsayısı 11 ve 12 yaşlar için çok iyi düzeyde, 13, 14 ve 11-14 yaşlar için iyi düzeydedir.

$\mathrm{Bu}$ çalışmanın sonuçlarına benzer olarak Lubans ve ark. (2) tarafindan yayımlanan sistematik derlemede yer alan bazı araștırmalarda SA anketlerinin test-tekrar test güvenirlik katsayılarının orta düzeyde olduğu belirtilmiştir. Helmerhorst ve ark. (23) FA anketlerinden elde edilen SA'nın güvenirlik katsayılarının değerlendirildiği sistematik derlemede medyan kore- lasyonlarının kabul edilebilir seviyede olduğunu belirtmişlerdir. Gençlerin serbest zaman sedanter davranışlarının incelendiği Youth Leisuretime Sedentary Behavior Questionnaire'in güvenirlik çalışmasında test-tekrar test güvenirlik katsayısının orta ve yüksek düzeyde olduğu görülmüştür (24). Sedanter davranış düzeyini belirleyen anketlerden elde edilen güvenirlik katsayılarının genel itibariyle kabul edilebilir seviyede olduğu görülmektedir. $\mathrm{Bu}$ açıdan bakıldığında, SA'yı test eden güvenirlik çalışmalarının sonuçlarıyla uyumlu olan ASAA'nın güvenilir bir anket olduğu kanısına varılmıştır.

Lubans ve ark. (2) sistematik derlemelerinde genellikle sedanter davranışların güvenirlik katsayılarının hafta içi günlerde hafta sonu günlerden daha yüksek olduğunu belirtirken, bu çalışmada 11-14 yaş için ele alındığında hafta sonu günlerinde bütün kategorilerin dahil olduğu sedanter sürenin toplamına ait sınıf içi korelasyon katsayısının iyi düzeyde (SKK=0,73), hafta içi günlere ait korelasyon katsayısının ise orta düzeyde $(\mathrm{SKK}=0,58)$ olduğu saptanmıştır. Hardy ve ark. (17) ve Guimarães ve ark. (25), testtekrar test yöntemiyle ASAA'nın güvenirliğini test etmiş ve SA'ya harcanan toplam sürenin hem cinsiyet hem de yaşa göre güvenirlik katsayılarının 0,70 'den daha büyük olduğunu belirlemişlerdir. Bu çalışmada ise ASAA'dan elde edilen tüm hafta sedanter davranış düzeyine bakıldığında 13, 14 ve 11-14 yaşlarda elde edilen sınıf içi korelasyon katsayısının iyi düzeyde olduğu, 11 ve 12 yaşları arasındaki öğrencilerin SKK'sının ise çok iyi düzeyde olduğu tespit edilmiştir. Dolayısıyla bu çalışmanın toplam haftaya ait sedanter davranış düzeyinin güvenirlik katsayılarının değerlendirilmesi bakımından Hardy ve Guimarães'in çalışmalarının bulgularını destekler nitelikte olduğu söylenebilir. Chinapaw ve ark. (26) sedanter aktivitelerde harcanan süreler bakımından ilk hafta ile ikinci hafta arasında farklılıkların görülebildiğini ve anketler ilk kez doldurulduğunda farklı aktivitelerde harcanan sürelerin adölesanlar tarafından daha iyi hatırlandığını belirtmişlerdir. Chinapaw ve ark. (26) tipik ve genel bir haftanın hatırlanmasını gerektiren anketlerin daha yük- 
sek test-tekrar test güvenirliğine sahip olduğunu belirtmişlerdir. Böylece bu çalışmada test edilen ASAA'nın bu özellikte bir anket olması, farklı aktivitelerde harcanan sürelerin daha doğru hatırlanmasını sağlayabilmektedir.

ASAA'nın kategorilerinden biri olan EKGRZ'a ait güvenirlik katsayısı tüm yaşlar için çok iyi düzeydedir. Adölesanlar üzerinde yapilan ASAA'nın güvenirlik çalışmasında ekran karşısında geçirilen süre, eğitim ve kültürel aktivitelere ait SKK'nın sosyal ve ulaşım aktivitelerden daha yüksek olduğu görülmüştür (17). Bu çalışmada ise ASAA'nın EKGRZ ve eğitim kategorilerine ait SKK'nın diğer kategorilerden daha yüksek olduğu görülmüştür.

Schmitz ve ark. (22) hafta içi ve hafta sonu günler için bilgisayar kullanımı ve televizyon izleme sıklığını değerlendiren kısa anketin güvenirlik katsayısının kabul edilebilir düzeyde olduğunu belirtmişlerdir. Ayrıca SA anketlerinde yer alan TV izleme ve bilgisayarda zaman geçirme gibi aktiviteler, araştırmacılar tarafından en güvenilir maddeler olarak kabul görmektedir (20). Busschaert ve ark. (20) ekran karşısında zaman harcamaya yönelik sedanter aktivitelerin (TV izleme gibi) daha yapılandırılmış ve düzenli aktiviteler olduğunu belirtmektedirler. TV izleme ve internet kullanımı gibi aktivitelerin SKK'larının daha yüksek olması, çocukların daha uzun ve kesintisiz bir şekilde bu tür aktivitelerde zaman harcamalarına dayandırılmaktadır. Dolayısıyla ekran karşısında geçirilen süreyle ilgili yapılan güvenirlik çalışmalarından elde edilen SKK'larının iyi düzeyde olduğu görülmektedir. Bunun yanı sıra sosyal aktiviteler ve seyahat aktivitelerine harcanan sürelerin miktarı değişkenlik gösterebileceği için periyodik olarak yapılan aktiviteleri temsil etmediği söylenebilir (25). Buna ek olarak çocuklarda organize aktivitelerin süresi ve tipinin hatırlanma olasılığı, serbest zamanlı aktivitelerden daha yüksektir. Hatırlanma olasılığındaki bu yükseklik, organize yapılan aktivitelerin tekrarlanabilirliğini artırmaktadır (27). Dolayısıyla ASAA'nın aktivite bileşenlerinden elde edilen SKK'nın, çocuklar tarafından yapılan aktivitelerin organize bir şekilde yapılıp yapılmamasına bağlı olarak değişebildiği görülmektedir.
Rey-Lopez ve ark. (28) adölesanlarda yaptıkları test-tekrar test güvenirlik çalışmasında kullanılan ekran zamanına dayalı SA anketinin geçerliğinin orta ve çok iyi düzeyde olduğunu, ancak internet kullanılarak ders çalışmaya ilişkin sürenin geçerlik katsayısının hafta içi zayıf, hafta sonu orta düzeyde olduğunu belirtmişlerdir. $\mathrm{Bu}$ çalışmada ise EGKRZ ve eğitim kategorilerinin yaşa göre değişmekle birlikte çoğunluğunun çok iyi ve iyi düzeyde olduğu görülmüștür. İnternet üzerinden yapılan akademik çalışmaların; ani, düzensiz ve aralıklı olması, çocukların doğru bir şekilde tahminde bulunmalarını zorlaştırması (28), bilgisayar ve internet kullanmaksızın ders çalışmanın daha planlı ve belirli bir zaman aralığında olması, ASAA'nın eğitim kategorisi de bilgisayar kullanarak ders çalşmanın yanı sıra bilgisayar kullanmadan ders çalışmayı da içerdiği için güvenirlik katsayısı kabul edilebilir düzeyde bulunmuş olabilir. Ayrıca sedanter aktivitelerde harcanan sürenin düşük olması, öğrencilerin sedanter davranışlarını ve harcadıkları süreleri daha kolay hatırlamalarını sağlayabilir (25).

\section{SONUÇ}

ASAA 11-14 yaşları arasındaki Türk çocuklarının hafta içi, hafta sonu ve tüm haftaya ait SA sürelerini beş kategoride değerlendirmek amacıyla kullanılabilecek geçerli ve güvenilir bir ankettir. ASAA ile haftanın her gününün ayrı değerlendirilebilmesi; süre, sıklık ve aktivite tipinin belirlenebilmesi; ekran karşısında geçirilen rekreasyonel zaman, eğitim, ulaşım, kültürel aktiviteler ve sosyal aktiviteler gibi kategorilere ayrılıyor olması; toplam SA süresinin belirlenebilmesi; ekran karşısında geçirilen süreye ilişkin önerilerin karşılanıp karşılanmadığı gibi verilere ulaşılabilmesi nedeniyle bu verilerin elde edilmesini amaçlayan çalışmalarda kullanılabileceği düşünülmektedir.

\section{KAYNAKLAR}

1. The Sedentary Behaviour Research Network (SBRN) (2019). What is sedentary behaviour?https://www.sedentarybehaviour.org/what-issedentary-behaviour/Erişim tarihi: 2 Şubat 2019.

2. Lubans DR, Hesketh K, Cliff D, et al. A systematic review of the validity and reliability of sedentary beha- 
viour measures used with children and adolescents. Obes Rev. 2011;12(10):781-99.

3. Tremblay MS, LeBlanc AG, Kho ME, et al. Systematic review of sedentary behaviour and health indicators in school-aged children and youth. Int J Behav Nutr Phys Act. https://doi.org/10.1186/1479-5868-8-98 2011;8(1):98.

4. Van der Ploeg HP, Hillsdon MJIJoBN, Activity P. Is sedentary behaviour just physical inactivity by another name? Int J Behav Nutr Phys Act. 2017;14(1):142. DOI 10.1186/s12966-017-0601-0

5. American Academy of Pediatrics (2019). American Academy of Pediatrics Announces New Recommendations for Children's Media Use. https://www.aap.org/en-us/about-the-aap/aap-pressroom/Pages/American Academy-of-PediatricsAnnounces-New-Recommendations-for-ChildrensMedia-Use.aspx./Erişim tarihi: 2 Şubat 2019.

6. Craggs C, Corder K, Van Sluijs EM, et al. Determinants of change in physical activity in children and adolescents: a systematic review. Am J Prev Med. 2011;40(6):645-58.

7. Janssen I, LeBlanc AG. Systematic review of the health benefits of physical activity and fitness in school-aged children and youth. Int $J$ Behav Nutr Phys Act. 2010;7(1):40. https://doi.org/10.1186/1479-5868-740

8. Hallal PC, Andersen LB, Bull FC, et al. Global physical activity levels: surveillance progress, pitfalls, and prospects. The Lancet. 2012;380(9838):247-57.

9. World Health Organization (2010). Prevalence of insufficient physical activity by country. http://www.who.int/gho/ncd/risk_factors/physical _activity/en/ Erişim Tarihi: 12 Haziran 2017.

10. Hills AP, Andersen LB, Byrne NMJBjosm. Physical activity and obesity in children. $\mathrm{Br} J$ Sports Med. 2011;45(11):866-70.

11. Bucksch J, Sigmundova D, Hamrik Z, et al. International trends in adolescent screen-time behaviors from 2002 to 2010. J Adolesc Health. 2016;58(4):417-25.

12. Guthold R, Cowan MJ, Autenrieth CS, et al. Physical activity and sedentary behavior among schoolchildren: a 34-country comparison. J Pediatr. 2010;157(1):43-9. e1. https://doi.org/10.1016/j.jpeds.2010.01.019

13. Loprinzi PD, Cardinal BJ. Measuring Children's Physical Activity and Sedentary Behaviors. J Exerc Sci Fit. 2011;9(1):15-23.

14. Chinapaw MJ, Mokkink LB, van Poppel MN, et al. Physical activity questionnaires for youth. Sports Med. 2010;40(7):539-63.

15. Daugbjerg SB, Kahlmeier S, Racioppi F, et al. Promotion of physical activity in the European region: content analysis of 27 national policy documents. J Phys Act Health. 2009;6(6):805-17.
16. Treuth MS, Hou N, Young DR, et al. Validity and Reliability of the Fels Physical Activity Questionnaire for Children. Med Sci Sports Exerc. 2005;37(3):488-95.

17. Hardy LL, Booth ML, Okely AD. The reliability of the adolescent sedentary activity questionnaire (ASAQ). Prev Med. 2007;45(1):71-4.

18. Karaca A. Fiziksel Aktivite Değerlendirme Yöntemleri. 1 ed. Spor Yayınevi ve Kitabevi. Ankara;2017. p.67.

19. Barrett P. Assessing the reliability of rating data. 2001. https://www.pbarrett.net/presentations/rater.pdf

20. Busschaert C, De Bourdeaudhuij I, Van Holle V, et al. Reliability and validity of three questionnaires measuring context-specific sedentary behaviour and associated correlates in adolescents, adults and older adults. Int J Behav Nutr Phys Act. 2015;12(1):117. https://doi.org/10.1186/s12966-015-0277-2

21. Voss C, Dean PH, Gardner RF, et al. Validity and reliability of the physical activity questionnaire for Children (PAQ-C) and adolescents (PAQ-A) in individuals with congenital heart disease. PLoS One. 2017;12(4):e0175806. https://doi.org/10.1371/journal.pone.0175806

22. Schmitz KH, Harnack L, Fulton JE, et al. Reliability and validity of a brief questionnaire to assess television viewing and computer use by middle school children. J Sch Health. 2004;74(9):370-7.

23. Helmerhorst HHJ, Brage S, Warren J, et al. A systematic review of reliability and objective criterion-related validity of physical activity questionnaires. Int J Behav $\begin{array}{lll}\text { Nutr Phys } & \text { Act. 2012;9(1):103. }\end{array}$ https://doi.org/10.1186/1479-5868-9-103

24. Cabanas-Sánchez V, Martínez-Gómez D, EstebanCornejo I, et al. Reliability and validity of the youth leisure-time sedentary behavior questionnaire (YLSBQ). J Sci Med Sport. 2018;21(1):69-74.

25. Guimarães RdF, Silva MPd, Legnani E, et al. Reproducibility of adolescent sedentary activity questionnaire (ASAQ) in Brazilian adolescents. Rev Bras Cineantropom Desempenho Hum. 2013;15(3):276-85.

26. Chinapaw MJ, Slootmaker SM, Schuit AJ, et al. Reliability and validity of the Activity Questionnaire for Adults and Adolescents (AQuAA). BMC Med Res Methodol. 2009;9(1):58. https://doi.org/10.1186/14712288-9-58

27. Welk GJ, Wickel E, Peterson M, et al. Reliability and validity of questions on the youth media campaign longitudinal survey. Med Sci Sports Exerc. 2007;39(4):612-21.

28. Rey-López JP, Ruiz JR, Ortega FB, et al. Reliability and validity of a screen time-based sedentary behaviour questionnaire for adolescents: the HELENA study. Eur J Public Health. 2011;22(3):373-7. 
Ek 1. Adölesan Sedanter Aktivite Anketi (ASAA)

\section{Bu kısımdaki sorular senin oturarakya da uzanarakgeçirdiğin zamanla ilişkilidir}

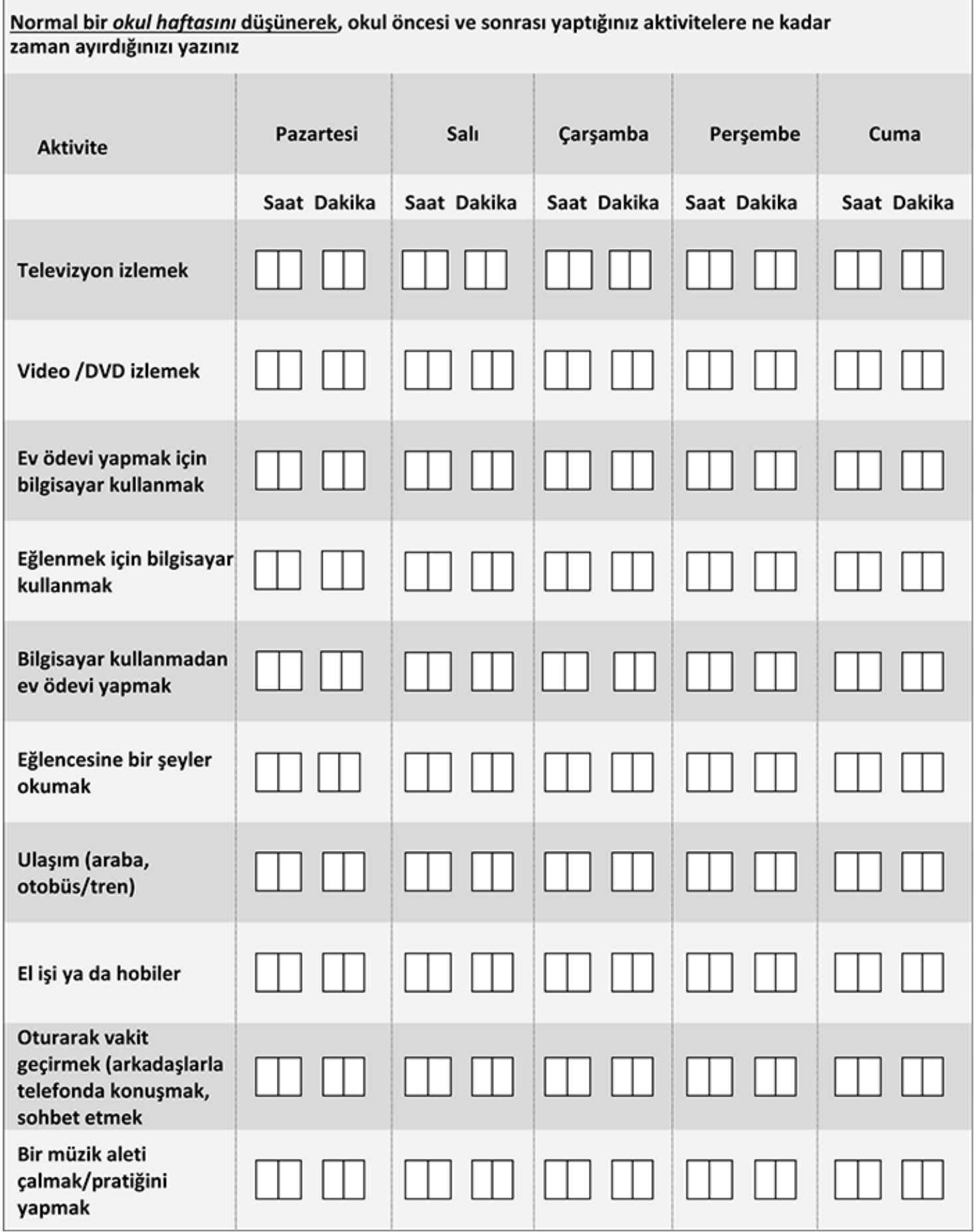


Normal bir hafta sonunu düşünerek, aşağıdaki aktiviteler için hafta sonunda ne kadar zaman ayırdığınızı yazınız

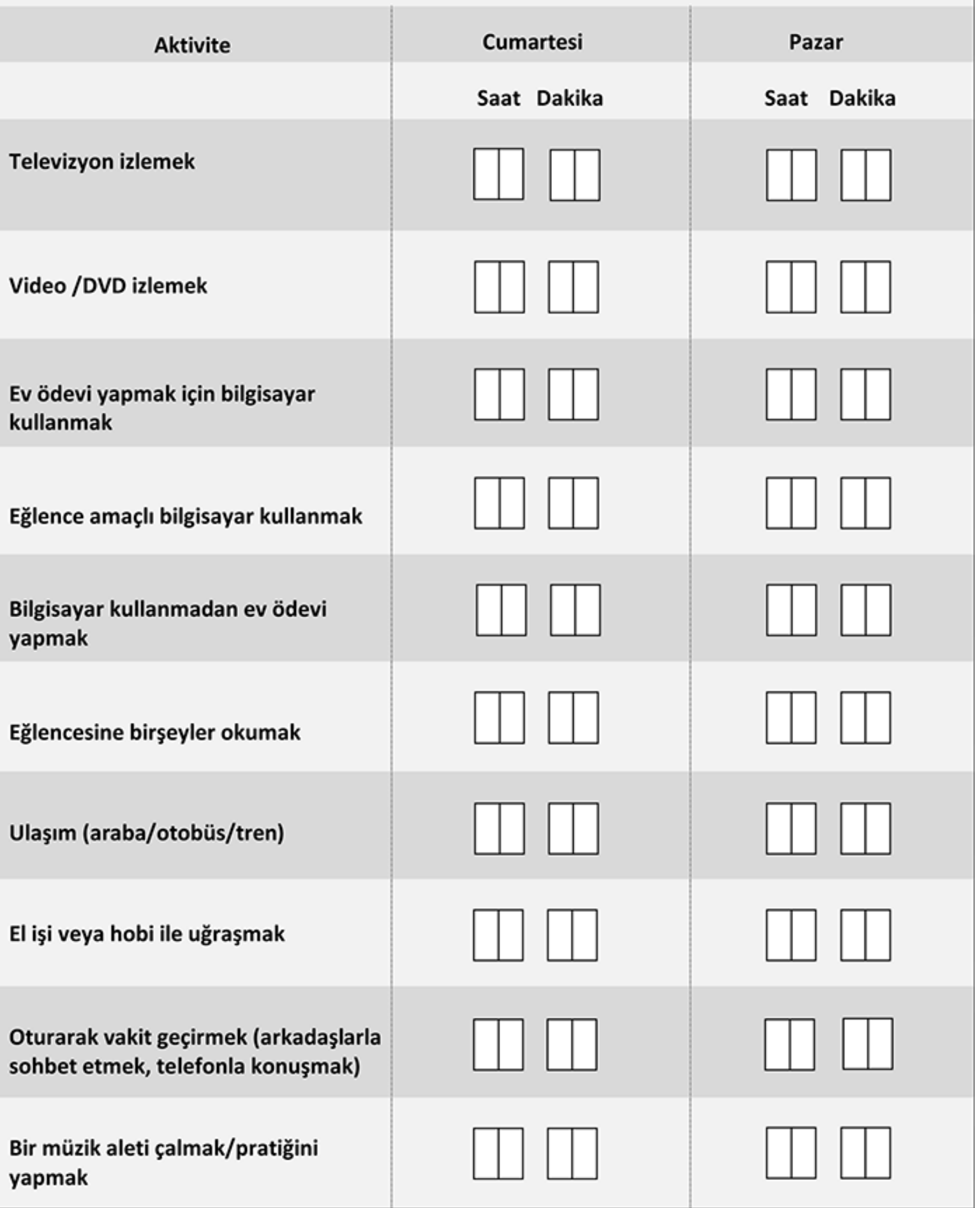

TEŞEKKÜR EDERIZ 